well-marked hesitancy in the intervals. One of these attacks was followed after a time by a general convulsion, and accompanied by signs of transitory mental change, and tremor of the right hand, but others were attended neither by convulsion, paralysis, nor loss of consciousness. Furthermore the patient positively asserted that he was able to read and write intelligently during some of the attacks, and his physician, confident that he understood accurately what was said to him. As regards the first point, Dr. Choate had noted, under the date of December 14th, that " under a little excitement in his oflice he was unuble to say to his assistant what he wished, but at once sat down and wrote, apparently without difficulty, what he had wished to say, but could not."

As regards the physiological explanation of the case, we may assume either that the speechlessuess was due to an irritation or "discharge" of the auditory area causing temporary inhibition of the speech functions, sufficient to prevent expression, yet not enough to wholly destroy the comprehension of simple matters, or to circulatory interference with the conducting tracts; or to increase in the general cerebral pressure, leading to anmmia and odema, and to loss of the speech functions on account of its relative sensitivo. ness. Of these suppositions the third seems the most probable, but whether it be correct or not, the case is instructive as showing the danger in assuming a lesion of the lower frontal convolution, even where loss of vocabulary seems the prominent symptom, and loss of the comprehension of speech relatively slight. 'Tho position of the tumor makes it probable that the later loss of the use of written symbols was due to disturbance of the visual area or its connections, but it certainly was not sufficiently pronounced to positively justify this diagnosis. A frontal position of the tumor seemed further indicated by the localized tremor-like convulsion of the fingers and wrist-muscles, with event. ual loss of power in the extensors of the fingers; but it now seems evident that these symptoms indicated only a relatively great mobility or instubility on the part of the corresponding flexor centres, und a greater vulnerability on the part of the extensor centresfacts which are quite in accordance with well-known principles.

With regard to the evidences of disturbance of the specific functions of the parietal lobe, in which the tumor lay, the only signs of loss of muscular sense Were that early in January, while the patient was still in pretty good condition, his assistant noticed that his hand would occasionally slip off from the table or desk without his knowledge; that he had some difficulty in forming his letters and holding his pen, and that the gait became unstendy; but these symptoms might be attributed, perhaps, to general cerebral pressure.

The movements of the upper eyelids during the convulsive attacks of the last few days of life gains in interest from the fact that such movements have, been located by Landouzy and Grasset (quoted by Gowers) in the inferior parietal lobule.

One point is worthy of notice as regards the patient's inability to express himself in long sentences (which he would fuil to complete, saying that he had forgotten what he had meant to say), namely, that this may be due to the condition first commented upon by Grashey, in which aphasia results from a loss of retentive power of the ganglionic matter, probably from impairment of its uutrition.
The aphusic symptoms in Caee II are of interest, partly as supporting the usual opinion as to localization of the functions, partly as showing the caution with which it is to be applied.

In spite of the fact that the new growth, with the subsequent softening, had almost destroyed the second left temporal convolution, the loss of the power of comprehension of speech was not complete, though, at one time, porhaps out of proportion to the limitation of the vocabulary. After a time, the general mental failure made the accurate study of tho less marked symptoms impossible, and the disorder of the circulation disturbed the action of all the cerebral centres. The most marked early symptom referable to the language functions was the alexia.

'The patient's mental condition and unwillingness to submit to closer examination, made it very difficult to study this symptom but its presence muy fuirly be attributed mainly to the presence of the tumor in the parietal lobe.

\section{OPLRA'TION IN A CASE OF CEREBRAL 'TUMOR.'}

HY II, H. A. HEA (II, M.D.,

Visiting Suryeon, Mressachusetts General Hospitul.

'Tux condition of the patient when he entered the Massachusetts General Hospital, March 1, 1889, was almost hopeless. Dr. J. J. Putnam, who had been watching him for some months, stated that it was only within a few days that he had presented symptoms justifying operative measures. IIe had been rapidly losing strength, and on the day of his udmission had a convulsion which seriously involved the heart. 'The surgical staff of the hospital were unanimous with Dr. Putnam and myself in the belicf that every day an operation was delayed his chances were materially lessened, and that he was entitled to the benefit of an exploratory trephining.

The operation was performed on the following day, the head having been shaved and the scalp made thoroughly aseptic. Careful attention was paid to the instruments and dressings, while the surroundings were those of the new aseptic thentre and ward of the hospital. A semi-lunar flap three and a half inches long was reflected from the area covering the second frontal convolution. 'This was rapidly dissected up and all bleeding vessels tied. The centrnl point for the trephine having been previously marked in the flap by a suture, a trephine of one inch diameter was made to perforate the bone which proved to be of unusual thickness and density (ut least three times that usually found in this locality). Upon reaching the dura mater, it was seen projecting into the cavity left by the trephine, firm and unyiclding, showing great intra-cranial pressure. It was evident that the opening would afford insufficient roon for the examination or removal of what appeared to be beneath the surface of the brain. A second opening was trephined a little higher and posterior to the first, and the spurs of bone lying between them were removed by boneforceps, making an oval opening two inches long by one inch broad. A flap of dura mater was turned up, exposing the bulging brain substance which was carefully explored with the scalpel to the depth of an inch. 'There was no undue hamorrhage, no serum, no pus. It was then thought best to explore very carefully the

1 Roud bofore the Boston Socloty for Modical Observation, May ti, 1889, reforring to Cays III of the precenling artiele. 
four surfaces of the wound with the finger, to determine the question of tumor. Nothing unusual could be felt in either direction. The only abnormal thing observed was an unusual toughness and thickness of the dura.

Although great care had been taken in his anasthesia and no unusual quantity of blood had been lost, the patient's pulse becamo very feeble, and it was thought prudent not to subject him to further exploration. 'The wound was carefully closed without replacing the bone, for the pressure from within the skull was so great as to make it impossible to do so. An antiseptic dressing was applied, heaters and stimulants used, and he was removed to his bed. He had a good reaction, his temperature rising to $103^{\circ}$ at ten o'clock on the night following, and his pulse 110. On the following morning his temperature was $991^{\circ}$, his pulse 85 , and respirations 25 . 'There had been no recurrence of convulsions, nor had he recovered consciousness, but had been comatose since the operation. From this time his temperature gradually rose until the following day at half-past live, when it reached $108 \frac{1}{2}^{\circ}$, just before death; the pulse and respiration increasing in frequency and diminishing in strength. With the results of the autopsy, you are alrealy familiar from Dr. Putnam's description.

'The case has been reported, not alone for its intrinsic interest, but for any value it may possess for others in the comparative study of unusual cases; as, for instance, certain anatomical specimens are only valuable through their classificution with others. Investigation and treatment may be conveniently divided into three sections:

(1) That connected with the diugnosis and localization of symptoms.

(2) The operation und its details.

(3) Tho after-treatment.

The first has been thoroughly disposed of by Dr. Putnam, but I will add, with his acquiescence, that as far us one case goes, this one is interesting in helping to establish the fact that intra-cranial pressure from a tumor may cause such symptoms, by the irritation of a more sensitive region at a distance, as to mislead the operator in the location of the growth. Other things being equal, such a condition would be most likely to occur in large tumors, and, consequently, in those least suitable for surgical treatment.

With regard to operative details, it is probable that the earlier stages are likely to be simple in character and confined to the reflection of a flap of skin and periosteum of varying size, yet so planned as to permit the freest drainage and the arrest of such hxmorrhage as may ensue. The latter should be easily controlled by a rubber tube applied about the head and below the point of incision. In this case the bleeding vessels were secured by snap forceps. It may be a useful point in practice to mark the centre for the trephine in the flap by a suture rather than to depend upon nitrate of silver for the marking, which might be eusily lost sight of during the process of disinfection. It seems to me that the first exploration should be made with a trephine of at least an inch and a half diameter ; for, in many instances it might furnish all the opening that would be essentiul.

In that way the time required for a second trephining, which might be cousiderable if the skull were as thick as in this instance, would be saved. A practical point in replacing the button of bone in the wound occurred to me, but unfortunately I could not avail myself of it on account of the great pressure from within the crunial cavity. This was to notch the bone and the corresponding edge from which it was removed with the saw, that when it should be replaced the sawn blood channels of the diploe could be properly matched, believing that the nutrition of the bone would be better provided for by a continuous channel, and a greater chance of its living thus secured. The question of how much can be done in the way of exploration after opening the dura is un important and practical one, and for the present must be left to the discretion of the operator and his advisers at the time. 'The needle, the knife and the finger havo their advocates, as shown in published reports, and while my instinct is against exploring the wound in the brain with the finger, on account of the contusion that seems inevitable, I cannot ignore the contrast between a well-calculated manipulation of such description by a competent surgeon and the rough-and-tumble bruising and laceration of the soft and hard parts incident to a bad fracture of the skull, which are commonly seen in the accident rooms of any large hospital. Such cases may do well, as we all know, with attention to the removal of loose fragments, the arrest of hxmorrhage, and tho maintenance of un adequate aseptic condition of the wound and its surroundings. 'The needle or the knife alone would hardly be competent to decide some cases; time may give us a better substitute. Until it does I suppose we must be content with believing that cases dependent upon such exploration are probably so grave in their prognosis that it can make little or no difference with the result. It may be, as Dr. Putnam suggests, that other openings may furnish a way out of the difliculty. 'The special emergencies of intra-cranial hamorrhage and its complications, the particular resources to be applied in cases extraovdinary from the position of growtls or their attachments must depend upou the same skill and readiness of its application that have already distinguished many operators in the field of abdominal surgery where experience has taught so much. The after-treatment, with some unusual exceptions, resolves itself into the accepted formula for compound fractures of the skull; namely, adequate drainage and asepticism.

\section{THE ANA'TOMY OF THE BREAS'I ANI) AXILLA IN 'TIE OPERATION FOR CANCER.'}

$$
\text { BY W. M. CONAN'A, M.D. }
$$

'THrs paper was written to bring out the important anatomical points to be remembered in the complete operation for removiug a cancerous breast and the axillary lymphatics. It was also intended that it should serve as a guide to the younger surgeons, who, like myself, are just beginning to operate.

The patient, after the breast and axilla have been prepared so that they are aseptic, is etherized and placed on the table. By the aid of pillows, the patient is turued so that the side to be operated on will be upward. This enables the operator, by extension of the arm, to make the axillary space more superficial, and also enables him to get good light.

The incision for removal of the breast should be determined by the location of the tumor, and should

1 Read at the meotling of the Surgioal Soction of the Suftolk DisRead at the moeting of the Surgioal
trict Medicul Soclety, on February $8,1890$. 